\title{
UM RESGATE HISTÓRICO SOBRE OS AVANÇOS DA CIÊNCIA QUE ESTUDA A ADOLESCÊNCIA
}

\author{
Graziele Alves Flores'; Bruna Dedavid da Rocha ${ }^{2}$; Eduarda Dorneles'; Luana \\ Fietz da Silva Raznievski ${ }^{4}$; Natiele Jorge Santana ${ }^{5}$; Maclaine de Oliveira Roos ${ }^{6}$; \\ Rosane Gomes de Oliveira7; Regina Gema Santini Costenaro ${ }^{8}$
}

\section{RESUMO}

Objetivou-se conhecer acerca do historial sobre os avanços da ciência que estuda a adolescência. Trata-se de uma revisão narrativa investigativa da literatura, sendo realizado uma busca através das bases de dados: Medical Literature Analisys and Retriveal system online (MEDLINE), base de dados bibliográficas especializada na área de Enfermagem (BDENF) e Literatura Latino-americana e do Caribe em Ciências da Saúde (LILACS), através de duas plataformas, a Biblioteca Virtual em Saúde (BVS) e PubMed, no período de setembro de 2021. Os achados organizados e analisados resultaram em dois eixos temáticos: $O$ marco da adolescência ao longo dos anos e a análise da História da Adolescência no Campo da Pesquisa. Não se dispõe de evidências suficientemente explícitas que expliquem acerca do início concreto no marco inicial sobre a ciência que dispõe da iniciativa neste campo da pesquisa e nem dos motivos pelo qual tão poucos estudos sobre este historial são publicados.

\footnotetext{
${ }^{1}$ Acadêmica de Enfermagem da Universidade Franciscana (UFN). Bolsista edital FAPERGS-PPSUS Flores.graziele8@gmail.com

2 Enfermeira. Mestre em Saúde Materno Infantil. Coordenadora da Política de Saúde da Mulher em Santa Maria - RS. Brunadedavid.rocha@gmail.com

${ }^{3}$ Acadêmica de Enfermagem da Universidade Franciscana (UFN). Dorneleseduarda29@gmail.com

4 Pedagoga. Professora-coordenadora do PSE-Secretaria Municipal de Santa Maria - RS. luana.raz@edu.santamaria.rs.gov.br

${ }^{5}$ Acadêmica de Enfermagem da Universidade Franciscana (UFN). natielesantan@gmail.com

${ }^{6}$ Médica. Mestranda em Saúde Materno Infantil da Universidade Franciscana (UFN). Coordenadora das políticas de Primeira Infância Melhor, ISTs/ HIV e Saúde da Criança em Santa Maria - RS. maclaine@terra.com.br

7 Mestranda em Saúde Materno Infantil da Universidade Franciscana (UFN). Rosane.oliveira@ufn.edu.br

8 Enfermeira. Doutora em Enfermagem. Docente do curso de Enfermagem da Universidade Franciscana (UFN). Reginacostenaro@gmail.com
} 
Palavras-chave: História, Desenvolvimento, Adolescente.

Eixo Temático: Atenção Integral e Promoção à Saúde (AIPS).

\section{INTRODUÇÃO}

A adolescência é uma fase complexa e dinâmica do ponto de vista físico e emocional na vida do ser humano. É neste período em que ocorrem várias mudanças no corpo, que repercutem diretamente na evolução da personalidade e na atuação pessoal da sociedade. Há muita preocupação com essa etapa, especialmente com os seus aspectos comportamentais e adaptativos, alertados já em 1904, quando Stanley Hall, um dos primeiros estudiosos sobre o tema, definiu a adolescência como um período de tempestade e tensão negativas ou ainda não somente um período de transição e sim um momento da vida com características próprias que precisam ser respeitadas (VALLE; MATTOS, 2011; MORAES; WEINMANN, 2020).

Nas implicações legais, é considerada criança, o ser humano até doze anos incompletos, e adolescente aquele entre doze e dezoito anos. Nos casos descritos em lei, aplica-se este Estatuto às pessoas entre dezoito e vinte e um anos de idade (BRASIL, 2007). A abordagem histórica da temática adolescência se faz de muita importância no campo da pesquisa em saúde, uma vez que, para avançar nessa pauta, é necessário compreender o movimento da sua linha temporal, uma vez que, esta fase demanda atualizações e reconhecimento por ser em sua essência um assunto emergente em nossa sociedade.

É conhecida, a afirmação de que a adolescência é uma fase inerentemente problemática. Sabe-se que esta definição é oriunda de preconceitos e estereótipos que são herdados da teoria maturacionista. Há, de fato, um pensamento hegemônico defensor da ideia de que os adolescentes, ao não saberem lidar com as transformações biológicas, entrariam em conflito e teriam propensão a determinados comportamentos inadequados, algumas vezes não condizentes com o que é aceito socialmente (SOUZA; SILVA, 2018). A adolescência é subjugada por uma fase de transformações e rebeldia, a "arborescência" denominada popularmente com conotação negativa, quando na verdade, a idade é um aspecto pouco significante, 
quando se descobre, não conseguir lidar com as emoções, situações ou até mesmo mudanças.

Ao tratar da história das políticas de atenção à criança no Brasil do século $X X$, os estudos apontam que o atendimento a essa população ocorria no sentido de suprir necessidades emergenciais. São ações em grande parte oriundas da igreja católica, cabendo à igreja o exercício das tarefas relacionadas ao atendimento aos órfãos e crianças pobres, assim como aos doentes, aos idosos e às viúvas. A perspectiva do atendimento era, em momentos, correcional repressiva, e as vezes assistencialista, voltada para doação caritativa e sem interesses imediatos, movidas por valores de ordem religiosa (GARCIA, 2009).

A questão da adolescência pode ser abordada por diversas perspectivas teóricas, seja do campo da Sociologia, do Direito, da História ou da Psicologia. Está fora de questão conceber uma visão unitária sobre a adolescência, trata-se, pois, de escolher um ponto de vista em razão de um determinado problema ou aspecto que se procura elucidar (OLIVEIRA; FULGENCIO, 2010).

Mediante estas ideias, objetiva-se nesta pesquisa conhecer acerca do historial sobre os avanços da ciência que estuda a adolescência.

\section{METODOLOGIA}

Este estudo constitui uma revisão narrativa de literatura a qual descreve e discute o desenvolvimento de um determinado assunto sob o ponto de vista teórico. Constitui-se da análise da literatura publicada nos diversos meios de divulgação científica, interpretação e análise crítica pessoal do autor. Os artigos de revisão narrativa são publicações amplas, que discutem o "estado da arte" de um determinado assunto, sob ponto de vista teórico. O autor comenta a pesquisa de acordo com os resultados da investigação sobre determinada questão (ROTHER, 2007; DEPOLITO et al., 2020).

Dessa forma, o estudo foi motivado pela seguinte questão norteadora: o que se tem publicado sobre a história do desenvolvimento da ciência que estuda a adolescência? O período de busca dos artigos ocorreu no mês de setembro de 2021, por meio das bases de dados: Medical Literature Analisys and Retriveal 
system online (MEDLINE), base de dados bibliográficas especializada na área de Enfermagem (BDENF) e Literatura Latino-americana e do Caribe em Ciências da Saúde (LILACS), através de duas plataformas, a Biblioteca Virtual em Saúde (BVS) e PubMed.

Utilizou-se os descritores em Ciências de Saúde pelas definições DECS: história AND desenvolvimento AND ciência AND adolescência, nos idiomas português e inglês. Os critérios de inclusão dos artigos foram determinados a partir de pesquisas publicadas internacionalmente, sem recorte temporal para maior abrangência na busca. Foi definido como critérios de exclusão: artigos que não atendessem a temática proposta e a indagação do estudo.

Para a seleção dos artigos foi realizada a leitura dos títulos, dos resumos e, caso necessário, a leitura na íntegra, seguindo os critérios de inclusão e exclusão. Esse processo resultou na inclusão total de três (03) publicações, as quais compuseram o corpus deste estudo, sendo um (01) da LILACS, e dois (02) da MEDLINE. Os textos foram então utilizados para construir a fundamentação teórica na compreensão acerca dos avanços históricos da ciência que estuda a adolescência.

\section{RESULTADOS E DISCUSSÕES}

Apresenta-se a seguir, os resultados, inicialmente por meio de um quadro sinóptico, com os artigos selecionados para esta revisão narrativa, especificando a informação relativa ao seu código de identificação, título, objetivo e períodico/ano.

Quadro 1 - Quadro sinóptico demonstrativo dos estudos incluídos na pesquisa.

\begin{tabular}{|c|c|c|c|}
\hline Artigo & Título & Objetivo & Periódico/ano \\
\hline A1 & Adolescência em & Oferecer contribuições ao & Biblioteca \\
& debate: & debate da adolescência & Virtual em \\
& contribuições & enquanto uma categoria social e & Saúde \\
\hline
\end{tabular}




\begin{tabular}{|c|c|c|c|}
\hline \multicolumn{2}{|c|}{$\begin{array}{l}\text { EDUCAÇÃO, SAÚDE } \\
\text { E TECNOLOGIA } \\
26 \text { A } 28 \text { DE OUTUBRO DE } 2021\end{array}$} & \multirow[b]{2}{*}{$\begin{array}{c}\text { uma etapa particular do } \\
\text { desenvolvimento cultural dos } \\
\text { sujeitos. }\end{array}$} & \multirow[b]{2}{*}{ LILACS - 2018} \\
\hline & $\begin{array}{l}\text { teóricas à luz da } \\
\text { perspectiva } \\
\text { histórico-cultural }\end{array}$ & & \\
\hline $\mathrm{A} 2$ & $\begin{array}{l}\text { Política de saúde } \\
\text { mental da } \\
\text { criança e do } \\
\text { adolescente: } \\
\text { história e } \\
\text { caminhos para a } \\
\text { participação }\end{array}$ & $\begin{array}{c}\text { Discutir e refletir sobre o } \\
\text { desenvolvimento da atenção à } \\
\text { saúde mental de crianças e } \\
\text { adolescentes e os caminhos no } \\
\text { processo de ampliação da } \\
\text { participação destes sujeitos na } \\
\text { produção de políticas públicas. }\end{array}$ & $\begin{array}{l}\text { PubMed } \\
\text { Ciência e } \\
\text { Saúde } \\
\text { Coletiva - } \\
2019\end{array}$ \\
\hline A3 & $\begin{array}{c}\text { O tema da } \\
\text { adolescência na } \\
\text { saúde coletiva - } \\
\text { revisitando } 25 \\
\text { anos de } \\
\text { publicações }\end{array}$ & $\begin{array}{c}\text { Compreender o } \\
\text { desenvolvimento do } \\
\text { conhecimento científico sobre o } \\
\text { tema da adolescência expresso } \\
\text { em publicações dos anos de } \\
1996 \text { a } 2020 \text { da Revista Ciência } \\
\text { \& Saúde Coletiva }\end{array}$ & $\begin{array}{c}\text { Biblioteca } \\
\text { Virtual em } \\
\text { Saúde } \\
\text { Medline - } \\
2020\end{array}$ \\
\hline
\end{tabular}

Fonte: Elaborado pelas autoras.

Após leitura, minuciosa dos artigos, emergiram dois eixos temáticos como guia de discussão denominados, conforme segue.

\section{1 - O marco da adolescência ao longo dos anos}

A origem da adolescência não é clara, pois nasceu discretamente na sociedade, nos meios burgueses, no decorrer do século XVIII, a partir de uma transformação que envolveu a afetividade no seio familiar, consagrando a invenção da infância. Solidificou-se paulatinamente ao longo do século XIX, período em que iniciou a escola obrigatória pelas leis Ferry (BRETON, 2017). Os serviços de atenção a crianças e adolescentes, no Brasil do século XX, eram movidos por valores 
religiosos, ora de caráter emergencista, em que muitos são julgados, ora assistencialista específico de caridade (GARCIA, 2009).

No estudo $A 1$, o autor relata acerca da concepção do psicólogo Vigotski quando aponta que o surgimento do pensamento em conceitos, constituindo-se como o principal diferencial no desenvolvimento cultural dos adolescentes. A puberdade chamada para conceituar a passagem da infância para a vida adulta, em um ponto de vista comum ao desenvolvimento do amadurecimento, e as reflexões tidas como uma intelectualização do desenvolvimento, são pontos chaves que se comungam para estabelecer esta fase.

Entretanto, ao compreender o desenvolvimento da ciência que estuda a adolescência, constata-se que esse tema era abordado de maneira muito complexa, na antiguidade, devido a não existência de políticas e serviços de saúde direcionados para esta fase do ciclo evolutivo. A história menciona que no período de transição para a vida adulta a atenção das comunidades relacionava-se a castidade e o casamento. Esse período não aparentava ser fonte de maiores preocupações, pois os filhos seguiam o trabalho ou profissão dos pais ou da situação social das famílias e assim, os filhos de artesãos seguiram artesãos, os que pertenciam à nobreza feudal se encaminharam para a vida militar ou religiosa e os filhos de camponeses seguiram a vida de camponês (LEVISKY, 2004).

O estudo A2, cita que ao longo da história, foram criadas para crianças e adolescentes, instituições com modelos de atenção que não priorizavam o cuidado, e nem tinham como foco a reinserção social e a relação com outros setores sociais. Dessa forma o mesmo estudo ainda aponta, que este público sempre permeou em meio a vulnerabilidade, quando em suas únicas circunstâncias, transcorreram por abrigos para deficientes de perfil asilar, e/ou aquelas que eram diagnosticados como autistas ou psicóticos encontrados peregrinando em busca de assistência (GARCIA, 2009).

Dessa forma, o movimento pela redemocratização do país, no qual estava inserida a luta pela reforma psiquiátrica, proporcionou visibilidade nas discussões que versavam sobre a necessidade de olhar as crianças e adolescentes como cidadãos. A Constituição Federal de 1988 afirmou a cidadania das crianças e dos 
adolescentes, condição de sujeitos de direitos que resultou na promulgação da Lei n. - 8.069/90, o ECA (BRAGA; OLIVEIRA, 2019).

Para a infância e adolescência brasileira, o ECA sugere um olhar diferenciado para esta população, sendo a 1 legislação aprovada de acordo com a Convenção Internacional dos Direitos da Criança e do Adolescente. Esta Lei se apresenta com um novo paradigma ético, de direitos, em todas as suas dimensões, prevendo a proteção integral, substituindo as medidas de controle e repressão por uma perspectiva de direitos e de possibilidades, reconhecendo a criança e adolescente como sujeitos. O ECA resultou de discussões, dos fóruns, movimentos populares, e foi uma conquista construída historicamente no decorrer de um processo que se prolongou por várias décadas e que envolve diferentes segmentos da sociedade (GARCIA, 2009).

Com efeito, o ECA é um marco histórico para a construção de novas políticas e modos de atenção voltados para a população infantojuvenil. No que se refere especificamente à atenção a crianças e adolescentes com sofrimento psíquico, a consolidação do ECA, concomitantemente com o processo de reforma psiquiátrica e a implantação da Política Nacional de Saúde Mental, exigiu a reestruturação da atenção à saúde mental de crianças e adolescentes (BRAGA; OLIVEIRA, 2019).

O ECA, além de preconizar o cuidado da criança e adolescente em todas as suas dimensões, também sinalizou a comunidade científica sobre a necessidade de descobrir e produzir novos conhecimentos caracterizando as necessidades físicas, emocionais, biológicas e sociais de crianças e adolescentes. Esta população, até então marginalizada, passa a ter um novo olhar da sociedade, uma atenção integral de acordo com suas especificidades, que Ihes são peculiares.

\section{2 - A análise da História da Adolescência no Campo da Pesquisa}

O estudo A3, aborda importante pesquisa sobre a adolescência, mostrando as fragilidades do sistema, o qual muitas vezes, direciona a assistência de maneira fragmentada, além de mostrar que a adolescência é uma área da ciência pouco estudada. O estudo analisou 432 publicações, sendo que, 68\% investigaram temáticas recorrentes envolvendo adolescentes, sendo que em síntese, nos 
atributos individuais aparecem temas como: alimentação, nutrição, transtorno alimentar, autoestima, aleitamento materno. Nos atributos familiares são descritos: ausência paterna, paternidade na adolescência, e nas relações entre pares está: ausência de relação, comportamento social, dificuldades/ rejeição, dentre outros (ASSIS; AVANCI; SERPELONI, 2020).

O mesmo estudo mostra no atributo saúde/doença: uso de drogas - cigarro, álcool, crack, medicação e outras drogas. No aspecto de acidentes e violência, mostra: violência - auto infligida, interpessoal, entre namorados, na escola, familiar. $\mathrm{Na}$ abrangência social e de atuação profissional, de serviços de saúde e outras instituições, mostra: padrão socioeconômico/renda, qualidade de vida, atuação profissional/ abrigos/ serviços de acolhimento e reintegração familiar, escola, atuação institucional, incluindo CAPSi, ESF, dentre outras.

Os resultados do estudo de $A 3$, mostram o crescimento significativo das pesquisas sobre adolescência na revista C\&SC nos últimos 25 anos, o que reflete sua robusta inserção e ascensão no campo da saúde pública. São estas pesquisas científicas que marcam e mostram a transformação de uma história que antes, de ser estudada, era oprimida e insignificante, e após as evidências científicas, passa a ter uma atenção voltado diretamente as suas principais necessidades.

Não se dispõe de evidências suficientemente explícitas que expliquem acerca do início concreto no marco inicial sobre a ciência que dispõe da iniciativa neste campo da pesquisa e nem dos motivos pelo qual tão poucos estudos sobre este historial são publicados. Em vista disso, espera-se que mais estudos como este possam ser realizados, e que a história desta temática seja discutida pela comunidade acadêmica com mais frequência, no intuito de engrandecer uma questão socioeducativa emergente, que merece seu reconhecimento e relevância nos diferentes níveis da atenção em saúde.

\section{CONCLUSÃO}

A adolescência em síntese foi uma fase marcada inicialmente por diferentes pontos de vista, como uma história materializada culturalmente, nas diferentes relações sociais da sociedade. Além de ser uma fase complexa de mudanças nas 
dimensões do ser humano ao conseguir lidar com as transformações divergentes do coletivo, culmina em seu historial, descontentamento na compreensão ao descaso e sofrimento em que a população adolescente, transitou ao longo dos anos.

A partir da compreensão deste resgate histórico, percebe-se também que esta temática se desenvolveu no que tange às diretrizes, princípios e políticas públicas na idealização de uma assistência de saúde melhorada para crianças e adolescentes. O ECA significou um grande avanço neste campo, uma vez que direciona novos olhares para a atenção da população infanto-juvenil, desmistificando o fazer assistencialista, pautado somente, no processo saúde-doença.

Por outro lado, denota-se a carência de estudos e publicações voltados para o campo historial da essência da temática, uma vez que este assunto revela a importância na área da pesquisa em saúde. É assim que fica o questionamento relacionado a história de uma determinada ciência: como aprimorar, um serviço de saúde de qualidade e baseado nos princípios do Sistema Único de Saúde - SUS, quando se desconhece a narrativa de sua história do passado até a contemporaneidade? Nesse sentido é necessário investir em artigos que apresentam a história do desenvolvimento da ciência que estuda a adolescência uma vez que estes, são ainda incipientes e limitados.

\section{AGRADECIMENTOS}

A Fundação de Amparo à Pesquisa do Estado do Rio Grande do Sul FAPERGS, junto ao Programa de Pesquisa para o SUS - PPSUS.

\section{REFERÊNCIAS}

ASSIS, S. G. D; AVANCI, J. Q; SERPELONI, F. O tema da adolescência na saúde coletiva - revisitando 25 anos de publicações. Ciência e Saúde Coletiva, Rio de Janeiro, v. 25, n. 12, p. 4831-4842, jun./ 2020. Disponível em: https://www.scielo.br/j/csc/a/ZtYhGrpPqXPzYVk3fmFz7Rs/?lang=pt. Acesso em: 22 set. 2021. 
BRAGA, C. P; OLIVEIRA, A. F. P. L. Políticas públicas na atenção á saúde mental de crianças e adolescentes: percurso histórico e caminhos de participação. Psicologia em estudo, Rio de Janeiro, v. 24, n. 2, p. 401-410, dez./ 2019. Disponível em: https://www.scielo.br/j/csc/a/g8DhKGKM65b36RLJdDHqhLP/?lang=pt. Acesso em: 24 set. 2021.

BRASIL. Ministério da Saúde. Marco Legal Saúde, um Direito de Adolescentes. Série A. manuais técnicos. 2007. Disponível em: https://bvsms.saude.gov.br/bvs/publicacoes/07_0400_M.pdf. Acesso em: 22 set. 2021.

BRETON, D. L. Uma Breve História da Adolescência. 1. ed. Belo Horizonte: Editora PUC Minas, 2017. p. 1-160.

DEPOLITO, S. C. P. et al. Atuação da Equipe de enfermagem frente ao desmame precoce: uma revisão narrativa. Saúde Coletiva, Paraná, v. 10, n. 55, p. 2915-2919, jul./ 2020.2 Disponível em: http://www.revistas.mpmcomunicacao.com.br/index.php/saudecoletiva/article/view/85 4/943. Acesso em: 25 set. 2021.

GARCIA, M. F. A constituição histórica dos direitos da criança e do adolescente: do abrigo ao acolhimento institucional. Trabalho de conclusão de curso. 2009. Dísponível em: http://tcc.bu.ufsc.br/Ssocial283137.pdf. Acesso: 25 set. 2021.

LEVISKY, D. L. Um monge no divã. O adolescer de Guibert de Nogent (10551125?): uma análise histórico-psicanalítica. 2004. Tese (Doutorado em História Social) - Faculdade de Filosofia, Letras e Ciências Humanas, Universidade de São Paulo, São Paulo, 2004. doi:10.11606/T.8.2004.tde-19052005-173437. Acesso em: 25 set. 2021. 
MORAES, B. R. D; WEINMANN, A. D. O. Notas sobre a história da adolescência. Estilos da Cínica: Revista sobre a infância com problemas, Porto Alegre, v. 25, n. 02, p. 280-296, abr./2020. Disponível em: https://www.revistas.usp.br/estic/article/view/160346/163125. Acesso em: 25 set. 2021.

OLIVEIRA, D. M. D; FULGENCIO, L. P. Contribuições para o estudo da adolescencia sob a ótica de Winnicott para educação. Psicologia em revista, Belo Horizonte, v. 16, n. 01, p. 64-80, abr./ 2010. Dísponivel em: http://pepsic.bvsalud.org/pdf/per/v16n1/v16n1a06.pdf. Acesso em: 25 set. 2021.

ROTHER, E. T. Revisão sistemática X Revisão narrativa. ACTA Paulista de Enfermagem, São Paulo, v. 20, n. 02, jul./2007. Disponível em: https://www.scielo.br/j/ape/a/z7zZ4Z4GwYV6FR7S9FHTByr/?lang=pt. Acesso em: 25 set. 2021.

SOUZA, C; SILVA, D. N. H. Adolescência em debate: contribuições teóricas a luz da perspectiva histórico-cultural. Psicologia em estudo, Rio Grande do Norte, v. 23, n. 02, p. 2-12, nov.l 2017. Disponível em: https://www.scielo.br/j/pe/a/jKmy5CvDmf7p987ycXnVHPx/?lang=pt. Acesso em: 25 set. 2021.

VALLE, L. E. L. R. D; MATTOS, M. J. V. M. D. Adolescência: as contradições da idade. Rev. Psicopedagogia, v. 28, n. 87, p. 321-323, nov./ 2011. Dísponivel em: http://pepsic.bvsalud.org/pdf/psicoped/v28n87/12.pdf. Acesso em: 25 set. 2021. 